\title{
Antiretroviral therapy outcomes among adolescents and young adults in a Tertiary hospital in Kenya
}

\author{
Patrick Mburugu ${ }^{1}$, Peter Muiruri ${ }^{2}$, Nelly Opiyo $^{2}$, Justus Simba ${ }^{1}$, Jane Adunda ${ }^{3}$, \\ Rosemary Kawira ${ }^{4}$, Onesmus Gachuno ${ }^{5}$
}

1. Jomo Kenyatta University of Agriculture and Technology, Child Health and Pediatrics.

2. Kenyatta National Hospital, Kenya, Comprehensive Care Centre.

3. Jomo Kenyatta University of Agriculture and Technology, Biostatistics and Actuarial Sciences.

4. Jomo Kenyatta University of Agriculture and Technology, School of Nursing Sciences.

5. University of Nairobi, Department of Obstetrics and Gynecology.

\section{Authors contacts:}

Nelly Opiyo; nellyopiyo@gmail.com Justus Simba; jsimba@jkuat.ac.ke, Jane Aduda; jaduda@jkuat.ac.ke, Rosemary Kawira; rkawira@jkuat.ac.ke, Onesmus Gachuno; owgachuno@yahoo.com.

\begin{abstract}
Background: Limited data is available on the treatment outcomes of HIV infected adolescents and young adults (AYA) in sub-Saharan Africa. HIV-infected adolescents and young adults (AYA) are at high risk of developing antiretroviral treatment failure.

Objective: To determine the clinical, immunological and virologic outcomes of AYA at a tertiary hospital in Kenya.

Methodology: A longitudinal study was conducted among AYA age 10-24 years attending Kenyatta National Hospital comprehensive care center. Clinical data was abstracted from electronic medical records for study participants with at least 6 months of follow-up using a structured data abstraction sheet.

Results: A total of 250 AYA age 10 to 24 years were included. The median age was 16 years. The median CD4 cell count was 650.6 cells $/ \mathrm{mm}^{3}$ (IQR 350.7-884.0). More than half $\left(60.6 \%\right.$ ) of AYA had a CD4 cell count higher than 500 cells $/ \mathrm{mm}^{3}$. Overall, $76.9 \%$ of AYA had achieved viral suppression (viral load $<1000$ copies $/ \mathrm{ml}$ ). There was a significant increase in virologic failure with higher age and late adolescents and young adults were more likely to have a viral load $>1000$ copies/ $\mathrm{ml} \mathrm{p}<0.012$

Conclusion: The overall virologic suppression in this cohort of AYA was sub-optimal. Both immunological and virologic outcomes were worse among late adolescents (18-19 years) and young adults (20-24 years).

Keywords: Adolescents, HIV, Kenya, virologic suppression, young adults.

DOI: https://dx.doi.org/10.4314/ahs.v21i1.2S

Cite as: Mburugu P, Muiruri P, Opiyo N, Simba J, Adunda J, Kawira R, et al. Antiretroviral therapy outcomes among adolescents and young adults in a Tertiary Hospital in Kenya. Afri Health Sci. 2021;21: 1-7. https:/ / dx.doi.org/10.4314/abs.v21i1.2S
\end{abstract}

\section{Introduction}

Adolescents and young adults (AYA) represent an increasing proportion of people living with HIV in the world. Over 1.6 million adolescents age 10-19 and 5 million young people age 15-24 are living with HIV ${ }^{1}$. Out of these 1.5 million (89\%) HIV infected adoles-

\section{Corresponding author: \\ Patrick M Mburugu, \\ Department of Child Health and Paediatrics, \\ Jomo Kenyatta University of Agriculture \\ and Technology, Thika Road, \\ P.O Box 62,000 Nairobi 00200, Kenya \\ Telephone +254722347119 \\ Email: pmburugu@jkuat.ac.ke}

cents live in sub-Saharan Africa. Adolescents have low levels of testing, linkage and retention to care and poor adherence to antiretroviral treatment ${ }^{2,3}$. Consequently clinical, immunological and virologic outcomes in adolescents have consistently shown poor results ${ }^{4}$. The number of AIDS-related deaths among adolescents tripled between the year 2000 and $2015^{5}$.

Adolescents and young adults are at high risk of developing treatment failure and drug resistance, which has dire consequences in low resource settings such as Kenya, where there are limited choices of antiretroviral regimens. Across sub-Saharan Africa, many children who were infected at birth are now becoming adolescents. The number of adolescents and young adults on antiretroviral treatment has been increasing reflecting treatment success of HIV infected children ${ }^{6}$. 
AYA have unique characteristics that predisposes them to treatment failure and drug resistance such as poor insight into the disease and treatment ${ }^{7}$. This makes close follow up and frequent assessment of treatment outcomes necessary. The existing literature on improving treatment outcomes is mainly focused on children and adults, and very limited in regards to AYA. Despite major advances in treatment and access to antiretroviral treatment, little is known about treatment outcomes in this age group. The study assessed the treatment outcomes of AYA actively on follow up at a tertiary hospital setting to determine their clinical, immunological and virologic outcomes.

\section{Methods}

\section{Study Design}

A longitudinal study was conducted as part of an interventional study to determine the effect of mobile phone calls on retention to care among adolescents and young adults on care and treatment at Kenyatta National Hospital Comprehensive Care Clinic between January 2017 and November 2017. A review of medical records was performed to determine the clinical, immunological and virologic outcomes in AYA 10 to 24 years on active follow.

\section{Study Site}

The study was carried out at Kenyatta National Hospital Comprehensive Care Centre which at the time of the study had 9,915 active HIV patients on care and treatment, among them 362 adolescents age 15-19 years and 693 children between 0-14 years. Patient's data is entered into an electronic medical records database (IQ care) during routine clinic visits. Data on clinical variables, outcomes, treatment regimens and laboratory records were abstracted from the electronic medical records data which is routinely updated at each clinic visit. AYA are typically seen in the clinic monthly or every three months for clinical monitoring, with a bi-annual viral loads and CD4 cell count monitoring.

\section{Study Outcomes}

The main study outcomes were improvement in WHO staging, immunological status and virologic failure. Immunological failure was defined as CD4 cell count $<$ 500 cells $/ \mathrm{mm}^{3}$ and virologic failure as a viral load of $>$ 1000 copies $/ \mathrm{ml}$.

\section{IRB Approval}

The study was approved by Kenyatta National Hospital/University of Nairobi Ethical Review Committee
(ERC) and University of Washington Institutional Review Board.

\section{Data Management and Statistical Analysis}

Data were collected and entered into a password-protected MS-Access database. The database was set within required limits and restrictions to reduce errors. Exploratory data analysis was carried out to identify extreme values and inconsistencies. On completion of the data entry, the data was exported into SPSS Version 21.0 for analysis.

Continuous values were summarized as means, medians, standard deviation and interquartile ranges. Discrete values were summarized using frequencies and percentages. Categorical variables were compared using chi-square test and Fishers exact test. Continuous variables were analyzed using Student t-test and Mann Whitney test by comparing means. A P value $<0.05$ was considered significant. The associations between social demographics characteristics and treatment outcomes were measured by Odds Ratios (OR).

\section{Results \\ Characteristics of the Study Population}

A total of 250 AYA age 10 to 24 years were included with a median age of 16 years. Of those in adolescence, $71(28.4 \%), 90(36 \%)$ and $59(23.6 \%)$ were in early (1013 years), mid (14-16 years) and late adolescence (18-19 years) respectively, while $30(12 \%)$ were young adults (20-24 years). Ratio of males 124 (49.6\%) vs females $126(50.4 \%)$ was almost 1 . Majority of the study participants $226(90.4 \%)$ had a parent as the primary caregiver while the rest had guardians. Almost half; 120 (48.2\%) attended clinics unaccompanied, while (90) 36.1\%, 23 (9.2\%), (6) $2.4 \% 10(4.0 \%)$ were accompanied by their mothers, fathers, siblings and guardians respectively. About two thirds $169(67.6 \%)$ attended all clinics as scheduled while a third 81(32.4\%) missed their scheduled clinics. There was no statistical difference on attendance of scheduled clinic visits among the various age groups $(\mathrm{p}=0.764)$.

\section{Treatment History}

All AYA in this study were on antiretroviral therapy (ART). The majority of $173(69.2 \%)$ were on a $1^{\text {st }}$ line antiretroviral regimen, while $77(30.8 \%)$ were on their $2^{\text {nd }}$ line regimen as per the national guidelines in Kenya. The most frequent ART regimen combination at ART initiation comprised of two nucleoside reverse transcriptase inhibitors (NRTIs); [zidovudine or abacavir or tenofovir or stavudine] plus lamivudine and one 
non-nucleoside reverse transcriptase inhibitor (NNRTI), nevirapine or efavirenz. Only a third ( 33 (13.2\%) were initiated on a protease inhibitor-based regimen. On the current ART regimen; majority 171 (68.4\%) were on two nucleoside reverse transcriptase inhibitors (NRTIs); [zidovudine or abacavir or tenofovir plus lam- ivudine] and one non-nucleoside reverse transcriptase inhibitor (NNRTI), [nevirapine or efavirenz]. Seventy seven $(30.8 \%)$ were on a protease inhibitor-based regimen while two $(0.8 \%)$ were on an integrase inhibitor-based regimen. (This is shown in Table 1). A review of records revealed that $85(34.0 \%)$ of study participants had a history of ART substitution.

Table 1: Antiretroviral Therapy Regimen at Kenyatta National Hospital Comprehensive Care Centre, Kenya 2017.

\begin{tabular}{|ll|}
\hline Initiation regimen & $\mathbf{n}(\mathbf{\%})$ \\
$\mathrm{D} 4 \mathrm{~T} / 3 \mathrm{TC} / \mathrm{NVP}$ & $1(0.4)$ \\
$\mathrm{TDF} / 3 \mathrm{TC} / \mathrm{NVP}$ & $2(0.8)$ \\
$\mathrm{AZT} / 3 \mathrm{TC} / \mathrm{NVP}$ & $47(18.8)$ \\
$\mathrm{ABC} / 3 \mathrm{TC} / \mathrm{NVP}$ & $11(4.4)$ \\
$\mathrm{TDF} / 3 \mathrm{TC} / \mathrm{LPVr}$ & $8(3.2)$ \\
$\mathrm{AZT} / 3 \mathrm{TC} / \mathrm{LPVr}$ & $7(2.8)$ \\
$\mathrm{D} 4 \mathrm{~T} / 3 \mathrm{TC} / \mathrm{EFV}$ & $4(1.6)$ \\
$\mathrm{TDF} / 3 \mathrm{TC} / \mathrm{EFV}$ & $37(14.8)$ \\
$\mathrm{AZT} / 3 \mathrm{TC} / \mathrm{EFV}$ & $63(25.2)$ \\
$\mathrm{ABC} / 3 \mathrm{TC} / \mathrm{EFV}$ & $50(20)$ \\
$\mathrm{TDF} / 3 \mathrm{TC} / \mathrm{ATVr}$ & $3(1.2)$ \\
$\mathrm{ABC} / 3 \mathrm{TC} / \mathrm{LPVr}$ & $15(6.0)$ \\
$\mathrm{RAL} / \mathrm{ATVr}$ & $1(0.4)$ \\
$\mathrm{TDF} / 3 \mathrm{TC} / \mathrm{DTG}$ & $1(0.4)$ \\
\hline $\mathrm{Current}$ regimen & $\mathbf{n}(\mathbf{\%})$ \\
$\mathrm{TDF} / 3 \mathrm{TC} / \mathrm{NVP}$ & $3(1.2)$ \\
$\mathrm{AZT} / 3 \mathrm{TC} / \mathrm{NVP}$ & $32(12.8)$ \\
$\mathrm{ABC} / 3 \mathrm{TC} / \mathrm{NVP}$ & $8(3.2)$ \\
$\mathrm{TDF} / 3 \mathrm{TC} / \mathrm{LPVr}$ & $14(5.6)$ \\
$\mathrm{AZT} / 3 \mathrm{TC} / \mathrm{LPVr}$ & $12(4.8)$ \\
$\mathrm{TDF} / 3 \mathrm{TC} / \mathrm{EFV}$ & $67(26.8)$ \\
$\mathrm{AZT} / 3 \mathrm{TC} / \mathrm{EFV}$ & $43(17.2)$ \\
$\mathrm{ABC} / 3 \mathrm{TC} / \mathrm{EFV}$ & $18(7.2)$ \\
$\mathrm{TDF} / 3 \mathrm{TC} / \mathrm{ATVr}$ & $29(11.6)$ \\
$\mathrm{AZT} / 3 \mathrm{TC} / \mathrm{ATVr}$ & $3(1.2)$ \\
$\mathrm{ABC} / 3 \mathrm{TC} / \mathrm{LPVr}$ & $15(6.0)$ \\
$\mathrm{ABC} / 3 \mathrm{TC} / \mathrm{ATVr}$ & $1(0.4)$ \\
$\mathrm{RAL} / 3 \mathrm{TC} / \mathrm{LPVr}$ & $1(0.4)$ \\
$\mathrm{RAL} / 3 \mathrm{TC} / \mathrm{DRV} / \mathrm{RTV}$ & $1(0.4)$ \\
$\mathrm{RAL} / \mathrm{ATVr}$ & $1(0.4)$ \\
$\mathrm{TDF} / 3 \mathrm{TC} / \mathrm{DTG}$ & $2(0.8)$ \\
\hline
\end{tabular}

\section{Treatment Outcomes}

Treatment outcomes 6 months after enrollment into the study showed that the mean body weight (SD) significantly increased from 46.3 (12.7) to 50.5 (11.1) $\mathrm{p}<0.001$, the WHO clinical staging significantly dete- riorated from stage I towards stage IV $\mathrm{p}=0.003$, there was no significant change in CD4 cell count $(>=500$ cells $/ \mathrm{mmm}^{3}$ Vs. $<500$ cells $\left./ \mathrm{mm}^{3}\right) \mathrm{p}=1.000$ and no significant changes in viral loads $(<1000$ copies $/ \mathrm{ml} \mathrm{Vs}$. $>=1000$ copies $/ \mathrm{ml}$ ) $\mathrm{p}=1.000$. (The results are shown in Table 2) 
Table 2: Comparison of Treatment Outcomes at Enrollment and at 6 Months, Kenyatta National Hospital Comprehensive Care Centre, Kenya 2017.

\begin{tabular}{|llll|}
\hline Variable & Enrolment & At 6 months & P value \\
Weight & & & \\
Mean (SD) & $46.3(12.7)$ & $50.5(11.1)$ & $<0.001$ \\
WHO clinical stage & & & \\
II & $215(86.0)$ & $193(79.4)$ & 0.003 \\
III & $19(7.6)$ & $28(11.5)$ & \\
IV & $14(5.6)$ & $19(7.8)$ & \\
CD4 cells count/mm & $2(0.8)$ & $3(1.2)$ & 1.000 \\
$>=500$ & $148(60.9)$ & $143(60.6)$ & \\
$<500$ & $95(39.1)$ & $93(39.4)$ & 1.000 \\
Viral load copies/ml & $188(75.2)$ & $186(76.9)$ & \\
$<1000$ & $62(24.8)$ & $56(23.1)$ & \\
$>=1000$ & &
\end{tabular}

\section{WHO Clinical Staging}

Overall at 6 months of the study a larger proportion of AYA were in WHO clinical stage I 193 (79.4\%), $28(11.5 \%)$ were in WHO clinical stage II, $19(7.8 \%)$ in WHO clinical stage III and 3 (1.2) in WHO clinical stage IV. At 6 months of the study there was no significant association in improvement in WHO clinical staging depending on gender, adolescent age group or the primary caregiver. Although not statistically significant, AYA who missed clinic appointments were more likely to move to an advanced WHO stage compared to those who did not miss appointments [OR 1.7(95\% CI 0.6-4.8), OR 1.0 (95\% CI), $\mathrm{p}=0.304]$. Those that had their regimen substituted were more likely to be in an advanced WHO clinical stage compared to those that were not OR 0.3 (95\% CI 0.1-0.8), 1.0 (CI 95\%) $\mathrm{p}=0.01$. (The results are summarized in Table 3 ).

Table 3: Factors associated with WHO clinical staging at 6 months, Kenyatta National Hospital Comprehensive Care Centre, Kenya 2017.

\begin{tabular}{|c|c|c|c|c|}
\hline \multirow[t]{2}{*}{ Variable } & \multicolumn{2}{|c|}{ WHO clinical stage at 6 months } & \multirow[t]{2}{*}{ OR (95\% CI) } & \multirow[t]{2}{*}{$P$ value } \\
\hline & I \& II & III \& IV & & \\
\hline \multicolumn{5}{|l|}{ Gender } \\
\hline Male & $106(48.0)$ & $14(63.6)$ & $0.5(0.2-1.3)$ & \multirow[t]{2}{*}{0.161} \\
\hline Female & $115(52.0)$ & $8(36.4)$ & 1.0 & \\
\hline \multicolumn{5}{|l|}{ Age } \\
\hline $10-13$ & $66(30.0)$ & 0 & & \multirow[t]{2}{*}{0.009} \\
\hline $14-17$ & $83(37.7)$ & $10(47.6)$ & 1.0 & \\
\hline $18-19$ & $45(20.5)$ & $6(28.6)$ & $0.9(0.3-2.6)$ & 0.853 \\
\hline $20-24$ & $26(11.8)$ & $5(23.8)$ & $0.6(0.2-2.0)$ & 0.427 \\
\hline \multicolumn{5}{|c|}{ Patient primary caregiver } \\
\hline Parents & $197(90.0)$ & $22(100.0)$ & - & \multirow[t]{2}{*}{0.236} \\
\hline Guardian & $22(10.0)$ & 0 & & \\
\hline \multicolumn{5}{|c|}{ Missed appointment } \\
\hline Yes & $74(33.5)$ & $5(22.7)$ & $1.7(0.6-4.8)$ & \multirow{2}{*}{0.304} \\
\hline No & $147(66.5)$ & $17(77.3)$ & 1.0 & \\
\hline \multicolumn{5}{|c|}{ Regimen substituted } \\
\hline Yes & $70(31.7)$ & $13(59.1)$ & $0.3(0.1-0.8)$ & \multirow[t]{2}{*}{0.010} \\
\hline No & $151(68.3)$ & $9(40.9)$ & 1.0 & \\
\hline
\end{tabular}

\section{Immunological Outcomes}

At 6 months of the study the median CD4 cell count for all age categories was 650.6 cells $/ \mathrm{mm}^{3}$ (IQR 350.7884.0). Considering all age categories, more than half $(60.6 \%)$ of AYA had a CD4 cell count with more than
500 cells $/ \mathrm{mm}^{3}$. There was a decrease in CD 4 cell count with higher age, with $92.3 \%$ of early adolescents (1013 years), $62.2 \%$ of mid adolescents (14-17 years), 38.8 $\%$ of late adolescents (18-19 years) and only $23.3 \%$ of young adults having a CD 4 cell count above 500 cells / $\mathrm{mm}^{3} \mathrm{p}<0.001$. (The results are shown in Table 4). 
Table 4: Trends in CD4+ Count and Viral Loads among AYA age Categories, Kenyatta National Hospital Comprehensive Care Centre, Kenya 2017.

\begin{tabular}{|c|c|c|c|}
\hline \multirow[t]{2}{*}{ Variable } & \multicolumn{2}{|c|}{ CD4 cells at 6 months } & \multirow[t]{2}{*}{ P value } \\
\hline & $>=500$ cells $/ \mathrm{mm}^{3}$ & $<500$ cells $/ \mathbf{m m}^{3}$ & \\
\hline \multicolumn{4}{|l|}{ Age } \\
\hline $10-13$ & $60(92.3)$ & $5(7.7)$ & $<0.001$ \\
\hline $14-17$ & $56(62.2)$ & $34(37.8)$ & \\
\hline $18-19$ & 19 (38.8) & $30(61.2)$ & \\
\hline $20-24$ & $7(23.3)$ & $23(76.7)$ & \\
\hline \multirow[t]{2}{*}{ Variable } & VL at $6 \mathrm{~m}$ & & P value \\
\hline & $\begin{array}{l}<1000 \\
\text { copies/ml }\end{array}$ & $>=1000$ copies $/ \mathrm{ml}$ & \\
\hline \multicolumn{4}{|l|}{ Age } \\
\hline $10-13$ & $58(87.9)$ & $8(12.1)$ & 0.012 \\
\hline $14-17$ & $73(78.5)$ & $20(21.5)$ & \\
\hline $18-19$ & $34(68.0)$ & $16(32.0)$ & \\
\hline $20-24$ & $19(61.3)$ & $12(38.7)$ & \\
\hline
\end{tabular}

On factors associated with CD4 cell count at 6 months, $\mathrm{p}<0.001)$ while young adults were more likely to have early adolescents were more likely to have a CD4 cell a CD4 cell count of less than 500 cells $/ \mathrm{mm} 3$ (OR 0.2 count more than 500 cells $/ \mathrm{mm}^{3}$ (OR 7.3 (2.7-19.9 (0.1-0.5 $\left.\mathrm{p}<0.001\right)$. (The results are shown in Table 5).

Table 5: Factors associated with CD4+ Count Level at 6 months, Kenyatta National Hospital Comprehensive Care Centre, Kenya 2017.

\begin{tabular}{|c|c|c|c|c|}
\hline Variable & $\begin{array}{c}\text { CD4 at } 6 \text { months } \\
>=500 \text { cells } / \mathrm{mm}^{3}\end{array}$ & $<500$ cells $/ \mathbf{m m}^{3}$ & OR (95\% CI) & P value \\
\hline \multicolumn{5}{|l|}{ Gender } \\
\hline Male & $71(49.7)$ & $44(47.3)$ & $1.1(0.7-1.9)$ & 0.725 \\
\hline Female & $72(50.3)$ & $49(52.7)$ & 1.0 & \\
\hline \multicolumn{5}{|l|}{ Age } \\
\hline $10-13$ & $60(42.3)$ & $5(5.4)$ & $7.3(2.7-19.9)$ & $<0.001$ \\
\hline $14-17$ & $56(39.4)$ & $34(37.0)$ & 1.0 & \\
\hline $18-19$ & $19(13.4)$ & $30(32.6)$ & $0.4(0.2-0.8)$ & 0.008 \\
\hline $20-24$ & $7(4.9)$ & $23(25.0)$ & $0.2(0.1-0.5)$ & $<0.001$ \\
\hline \multicolumn{5}{|c|}{ Patient primary caregiver } \\
\hline Parents & $129(90.8)$ & $84(90.3)$ & $0.9(0.4-2.4)$ & 0.904 \\
\hline Guardian & $13(9.2)$ & $8(8.7)$ & 1.0 & \\
\hline \multicolumn{5}{|c|}{ Missed appointment } \\
\hline Yes & $49(34.3)$ & $28(30.1)$ & $1.2(0.7-2.1)$ & 0.506 \\
\hline No & $94(65.7)$ & $65(69.9)$ & 1.0 & \\
\hline \multicolumn{5}{|c|}{ Regimen substituted } \\
\hline Yes & $38(26.6)$ & $45(48.4)$ & $0.4(0.2-0.7)$ & 0.001 \\
\hline No & $105(73.4)$ & 48 (51.6) & 1.0 & \\
\hline
\end{tabular}

\section{Virologic Failure}

At a reference point of 6 months ( 186 ) $76.9 \%$ of adolescents and young adults had a viral load $<1000$ copies $/ \mathrm{ml}$, while $93(39.4 \%)$ had a viral load of $>1000$ copies $/ \mathrm{ml}$. There was a significant likelihood of virologic failure with higher age; with young adults more likely to have a viral load $>1000$ copies $/ \mathrm{ml} \mathrm{p}<0.012$. (The results are shown in Table 4). Although not statistically significant early adolescents were twice as likely to have virologic suppression compared to other age categories in the study OR $2.0(0.8-4.8) \mathrm{p}=0.126$. (The results are shown in Table 6). 
Table 6: Factors associated with Viral Load suppression at 6 months, Kenyatta National Hospital Comprehensive Care Centre, Kenya 2017.

\begin{tabular}{|lllll|}
\hline Variable & $\begin{array}{l}\text { VL at } \mathbf{~ m o n t h s} \\
<\mathbf{1 0 0 0} \text { copies/ml }\end{array}$ & $\begin{array}{l}>\mathbf{1 0 0 0} \text { copies/ml } \\
\text { Gender }\end{array}$ & OR (95\% CI) & P value \\
Male & $87(46.8)$ & $32(57.1)$ & $0.7(0.4-1.2)$ & 0.174 \\
Female & $99(53.2)$ & $24(42.9)$ & & \\
Age & & & & \\
$10-13$ & $58(31.5)$ & $8(14.3)$ & $2.0(0.8-4.8)$ & 0.126 \\
$14-17$ & $73(39.7)$ & $20(35.7)$ & 1.0 & \\
$18-19$ & $34(18.5)$ & $16(28.6)$ & $0.6(0.3-1.3)$ & 0.168 \\
$20-24$ & $19(10.3)$ & $12(21.4)$ & $0.4(0.2-1.0)$ & 0.058 \\
Patient primary caregiver & $169(91.4)$ & $49(89.1)$ & $1.3(0.5-3.5)$ & 0.610 \\
Parents & $16(8.6)$ & $6(10.9)$ & 1.0 & \\
Guardian & & & & \\
Missed appointment & $64(33.9)$ & $16(28.6)$ & $1.3(0.7-2.5)$ & 0.458 \\
Yes & $123(66.1)$ & $40(71.4)$ & 1.0 & \\
No & & & & \\
Regimen substituted & $62(31.2)$ & $18(50.0)$ & $0.8(0.4-1.4)$ & 0.370 \\
Yes & $137(68.8)$ & $18(50.0)$ & 1.0 & \\
No & &
\end{tabular}

\section{Discussion}

Our study findings demonstrated that $76.9 \%$ of AYA in this cohort had achieved viral load suppression. Our study cohort viral load suppression was lower than the national average reported rate of $88.4 \%$ for patients $0-64$ years $^{8}$. The viral load suppression is slightly higher than the $67.1 \%$ found by KENPHIA among children aged $0-14$ years but much lower than the $90.6 \%$ among those 15-64 years of age. The relatively low rates of viral load suppression in AYA has been revealed in several other studies ${ }^{9,10}$. In our study, young adults were less likely to achieve adequate virologic suppression, followed by late adolescents. Majority of early adolescents $(87.9 \%)$ had achieved virologic suppression.

Median CD 4 cell count was 650 cells $/ \mathrm{mm}^{3}$, with $60 \%$ of adolescents having a CD4 cell count $>500$ cells/ $\mathrm{mm}^{3}$. This immunological response is consistent to study findings in Asia and South Africa where the median CD4 cell count was fond to be $657 \mathrm{cells} / \mathrm{mm}^{3}$ and 686 cells $/ \mathrm{mm}^{3}$ respectively ${ }^{11,12}$. A similar trend of higher virologic suppression among early adolescents compared to mid, late adolescents and young adults was observed with CD4 cell count, where majority of early adolescents had a better immunological outcome compared to the other age groups. This might be explained by parental oversight to treatment for early adolescents. More than half of late adolescents and young adults had CD4 cell count of $<500$ cells $/ \mathrm{mm}^{3}$. This trend of a decrease in CD4 cell count and increased chances of virologic failure with advancing age was observed in a study by Mburugu and colleagues (2016) where mid and late adolescents had poor immunologic, virologic outcomes and poor adherence to treatment ${ }^{13}$. Similarly Geoffrey and colleagues ${ }^{14}$ documented in a baseline characteristics study in South Africa that mid and late adolescents had lower median CD4 cell counts ${ }^{17}$. In the same study viral suppression was poorest in mid adolescents at any point time of ART. The poor immunological and virologic outcomes could be explained by less adherence support during transition to adult HIV programs leading to poor adherence to ART, less support from parents and guardians and complexities associated with the developmental stages of adolescence and young adulthood.

At our last assessment at 6 months, a larger proportion of AYA in our study ( $79.4 \%$ ) were in WHO clinical stage I, while $11.5 \%, 7.8 \%$ and $1.2 \%$ were in WHO clinical stage II, III and IV respectively. Thus majority of the adolescents were stable with absence of recent opportunistic infections. However on further analysis, during the six months study period, there was significant deterioration in the clinical staging from WHO clinical stage I to IV. The finding of having a majority of HIV infected adolescents being stable was also found in a longitudinal study by Allison et al where they found $85 \%$ of adolescents in there cohort to be stable. ${ }^{18}$

\section{Limitations}

This was a cross-sectional study that utilized routinely collected clinical outcome data from an electronic 
medical records system as part of a clinical trial. The study involved a single site which is a tertiary teaching hospital thus the results may have limited generalizability. However this study provides an insight into the treatment outcomes of HIV infected adolescents and identifies the age categories that need special attention during care and treatment for that age group.

\section{Conclusion}

Viral load suppression in this cohort of adolescents was suboptimal with late adolescents (18-19 years) and young adults (20-24 years) being more likely to have virologic failure. Interventions in this program should targets adolescents and young adults with special focus to late adolescents and young adults to improve treatment outcomes.

\section{Acknowledgments}

The authors appreciate the Afya Bora Consortium (ABC) Global Health Leadership fellowship program that funded this study. Gratitude's to the ABC working group members and the leadership of $A B C$ Global Health Leadership program. Special thanks to the adolescents and staff at Kenyatta National Hospital Comprehensive Care Centre.

\section{Conflict of interest}

Authors of this article disclose no conflict of interest in this study and its publication.

\section{References}

1. Adolescent HIV prevention [Internet]. UNICEF DATA. [cited 2020 Jul 28]. Available from: https:// data.unicef.org/topic/hivaids/adolescents-young-people/

2. Tanner AE, Philbin P, Ma O, A D, J E, B K, et al. Linking HIV+ adolescents into care: The effects of relationships between local health departments and adolescent medicine clinics. J HIV AIDS Soc Serv [Internet]. 2013 Jan 1 [cited 2020 Jul 28];12(3-4). Available from: https://europepmc.org/article/pmc/pmc3835468

3. Ulett KB, Willig JH, Lin H-Y, Routman JS, Abroms $\mathrm{S}$, Allison J, et al. The therapeutic implications of timely linkage and early retention in HIV care. AIDS Patient Care STDS. 2009 Jan;23(1):41-9.

4. Treatment outcomes in HIV-infected adolescents attending a community-based antiretroviral therapy clinic in South Africa | BMC Infectious Diseases | Full Text [Internet]. [cited 2020 Jul 28]. Available from: https://bmcinfectdis.biomedcentral.com/articles/10.1186/1471-2334-12-21
5. Adolescent deaths from AIDS tripled since $2000-$ UNICEF | Press centre | UNICEF [Internet]. [cited 2020 Jul 28]. Available from: https://www.unicef.org/ media/media_86384.html

6. Thorne C, Newell M-L, Botet F, Bohlin A-B, Ferrazin A, Giaquinto C, et al. Older Children and Adolescents Surviving With Vertically Acquired HIV Infection. JAIDS-Journal of Acquired Immune Deficiency Syndromes. 2002 Apr 1;29(4):396-401.

7. Antiretroviral medication adherence among the REACH HIV-infected adolescent cohort in the USA PubMed [Internet]. [cited 2020 Jul 28]. Available from: https://pubmed.ncbi.nlm.nih.gov/11177463/

8. KENPHIA-2018-PREL-REP-2020-HR3-final.pdf [Internet]. [cited 2020 Jul 28]. Available from: https:// www.health.go.ke/wp-content/uploads/2020/02/ KENPHIA-2018-PREL-REP-2020-HR3-final.pdf

9. Umar E, Levy JA, Bailey RC, Donenberg G, Hershow RC, Mackesy-Amiti ME. Virological Non-suppression and Its Correlates Among Adolescents and Young People Living with HIV in Southern Malawi. AIDS Behav. 2019 Feb;23(2):513-22.

10. Salou M, Dagnra AY, Butel C, Vidal N, Serrano L, Takassi E, et al. High rates of virological failure and drug resistance in perinatally HIV-1-infected children and adolescents receiving lifelong antiretroviral therapy in routine clinics in Togo. J Int AIDS Soc [Internet]. 2016 Apr 27 [cited 2020 Jul 28];19(1). Available from: https://www.ncbi.nlm.nih.gov/pmc/articles / PMC4850147/

11. Chokephaibulkit K, Kariminia A, Oberdorfer P, Nallusamy R, Bunupuradah T, Hansudewechakul R, et al. Characterizing HIV Manifestations and Treatment Outcomes of Perinatally Infected Adolescents in Asia. Pediatr Infect Dis J. 2014 Mar;33(3):291-4.

12. Anderson K, Muloiwa R, Davies M-A. Treatment outcomes in perinatally infected HIV-positive adolescents and young adults after $\geq 10$ years on antiretroviral therapy. South African Medical Journal. 2018 Dec 13;109(1):27-34.

13. Mburugu P, Muiruri P, Opiyo N, Theresa O, Osingada CP, Ngabirano TD, et al. Treatment outcomes of HIV infected adolescents attending a national referral hospital in Kenya. Annals of Global Health. 2016 Aug 20;82(3):513-4.

14. Geoffrey F, Eula M, Brian E, Ashraf R. ARV treatment outcomes of adolescent's: Comparison of baseline characteristics and antiretroviral treatment outcomes between Early, Mid and Late adolescents. Forthcoming, 2013. 